Is Brain-Derived Neurotrophic Factor Associated With Smoking Initiation? Replication Using a Large Finnish Population Sample : Replication Using a Large Finnish Population Sample

\title{
Korhonen, Tellervo
}

2020-02-06

Korhonen , T , Loukola , A , Hällfors , J , Salomaa , M-M , Salomaa , V \& Kaprio , J 2020 , ' Is Brain-Derived Neurotrophic Factor Associated With Smoking Initiation? Replication Using a Large Finnish Population Sample : Replication Using a Large Finnish Population Sample ' , Nicotine \& Tobacco Research , vol. 22 , no. 2 , pp. 293-296 . https://doi.org/10.1093/ntr/nty218

http://hdl.handle.net/10138/321651

https://doi.org/10.1093/ntr/nty218

acceptedVersion

Downloaded from Helda, University of Helsinki institutional repository.

This is an electronic reprint of the original article.

This reprint may differ from the original in pagination and typographic detail.

Please cite the original version. 


\section{IS BRAIN DERIVED NEUROTROPHIC FACTOR (BDNF) ASSOCIATED WITH SMOKING INITIATION? REPLICATION USING A LARGE FINNISH POPULATION SAMPLE}

Tellervo Korhonen, $\mathrm{PhD}^{1,2,3}$, Anu Loukola, $\mathrm{PhD}^{1}$, Jenni Hällfors, $\mathrm{PhD}^{1}$, Veikko Salomaa, $\mathrm{MD}, \mathrm{PhD}^{3}$, Jaakko Kaprio, MD, $\mathrm{PhD}^{1,2}$

${ }^{1}$ Institute for Molecular Medicine Finland (FIMM), University of Helsinki, Helsinki, Finland

${ }^{2}$ Department of Public Health, University of Helsinki, Helsinki, Finland

${ }^{3}$ National Institute of Health and Welfare, Helsinki, Finland

Corresponding author:

Tellervo Korhonen

Institute for Molecular Medicine Finland (FIMM)

University of Helsinki

Helsinki, Finland

E-mail: tellervo.korhonen@helsinki.fi 


\begin{abstract}
Introduction: Brain derived neurotrophic factor (BDNF) is a growth factor in the central nervous system. There is evidence for the involvement of BDNF in addictions and mental disorders. We aimed to replicate the earlier reported association of a functional genetic variant of $B D N F$ with smoking initiation (SI) using a large population-based sample, and to test whether the association is independent of depression.
\end{abstract}

Methods: Our sample was drawn from the Finnish population-based FINRISK Surveys conducted in 1992, 1997, 2002 and 2007. The BDNF Val66Met (G/A) variant (rs6265) was genotyped in 26,751 adults aged 25-74 years. SI phenotype was defined as self-reported ever $(n=12,543)$ versus never $(n=19,340)$ smoking. The association between BDNF Val66Met and SI was modeled using logistic regression adjusted for age and sex, and in secondary analyses also for depression $(n=26,647)$. Depression was defined as self-reported depression diagnosed or treated by physician during the past year.

Results: The sex and age adjusted analysis confirmed that the major (Val) allele increased the risk of being a lifetime ever smoker (per allele $\mathrm{OR}=1.07 ; 95 \% \mathrm{Cl} 1.01,1.12 ; \mathrm{p}=.01$ ). When depression, which itself was significantly associated with $\mathrm{SI}(\mathrm{OR}=1.58 ; 95 \% \mathrm{Cl} 1.37,1.82 ; \mathrm{p}<.001)$, was added to the model, the association of the gene with SI remained unchanged (per allele $\mathrm{OR}=1.06 ; 95 \% \mathrm{Cl} 1.01,1.12 ; \mathrm{p}=.01$ ). Exclusion of depressed individuals did not change the results $(\mathrm{OR}=1.06 ; 95 \% \mathrm{Cl} 1.01,1.12 ; \mathrm{p}=.02)$.

Conclusions: In a population dataset we replicated the earlier reported association of BDNF Val66Met with SI. Our data further suggest that this association is independent of depression. 


\section{Introduction}

Brain derived neurotrophic factor (BDNF) is a growth factor in the central nervous system. BDNF has an important role in the survival of existing neurons and in the growth and differentiation of new neurons and synapses. Autry and co-authors (1) summarized evidence for the involvement of BDNF in addictions, such as cigarette smoking, and mental disorders, such as depression. Genetic variation in $B D N F$ has been studied earlier in relation to cigarette smoking. An early meta-analysis suggested that BDNF SNPs are associated with initiation of cigarette smoking. These SNPs in the BDNF region include the Val66Met polymorphism (2) and the NTRK2 gene (3). Earlier literature further suggests that people with an altered BDNF signaling are more likely to become and remain addicted to nicotine. In humans, nicotine potentially causes BDNF release in the cortex and in the striatum (1). Thus, BDNF signaling may enhance the rewarding properties of cigarette smoking in the human brain.

In addition to evidence in humans, several animal studies have demonstrated the link between BDNF and nicotine. Long-term nicotine administration in rodents has been shown to lead to increased $B d n f$ expression in the brain (4). Also, it has been demonstrated in animals that nicotine enhances Ntrk2 transcription and protein expression in the cortex and the striatum and decreases Ntrk2 expression in the Ventral Tegmental Area (5).

A combined analysis of three large meta-analyses (the Tobacco and Genetics (TAG) Consortium, the ENGAGE consortium, and the Oxford-GlaxoSmithKline consortium) including a total of 143,023 persons identified altogether eight BDNF SNPs associated with smoking initiation. The most robustly associated variant was the Val66Met (rs6265). Importantly, no potential covariates apart from age and sex were taken into account. (6-8).

The first aim of the present study was to replicate the association between BDNF Val66Met and smoking initiation in a large population-based sample originating from the homogenous Finnish population. This sample did not contribute to the prior meta-analyses (6-8). Because BDNF has been found to associate also with depression, especially with increasing age (9) and among men (10) and because smokers are more often depressed than non-smokers (11-13), the reported association between BDNF and smoking could be confounded, mediated or moderated by depression. Thus, our second aim was to test whether the association between BDNF Val66Met and smoking initiation is influenced by depression. 


\section{Methods}

\section{Sample}

Our sample was drawn from the Finnish population-based national FINRISK Study which is a large population survey on risk factors of non-communicable diseases in Finland (14). Every five years since 1972, area, sex and age stratified random samples have been drawn from the Population Information System. The areas varied by study year, as Northeast and Southwestern Finland were represented each year, but Northern Finland only in later years (Oulu in 1997, 2002 \& 2007 and Lapland in 2002 and 2007, yet in Lapland only mailed questionnaire in 2007). We used data from the national FINRISK 1992, 1997, 2002 and 2007 surveys. FINRISK Studies have included a self-administered questionnaire, physical examination, and blood draw for laboratory analyses and extraction of DNA. The FINRISK studies have been approved by the Coordinating Ethics Committee of the Helsinki University Hospital District. Each participant has given a written informed consent.

\section{Genotyping}

DNA was derived from whole blood samples, which were frozen immediately at the clinical study sites. The samples were transferred to the National Institute of Health and Welfare (earlier National Public Health Institute), where the DNA was extracted. Genotyping of the BDNF Val66Met (G/A) variant was done under standard protocols of iPLEX Gold technology on the MasSARRAY System (Sequenom, San Diego, CA, USA) (15). The BDNF Val66Met (G/A) variant (rs6265) was genotyped in 26,751 adults aged 25-74 years. In the FINRISK data the major (Val) allele frequency was 0.84 . The success rate was $>0.99$ and the genotypes were in Hardy-Weinberg equilibrium ( $p=0.17)$. The genotype frequencies did not vary by study year (Chi-sq $p=0.60)$, but showed regional variation $(p=0.014)$

\section{Phenotypes}

Smoking initiation phenotype was defined as self-reported ever $(n=12,543)$ versus never $(n=19,340)$ smoking. In the questionnaire, participants were asked whether they had ever smoked. Those stating that they had never smoked were categorized as never smokers and were advised to skip the other smokingrelated questions. Among those who stated they had smoked at least once, the threshold for 'ever smoker' was defined as at least 100 cigarettes smoked in their lifetime. Those who had ever smoked less than 100 cigarettes in their lifetime were coded as 'never smokers'. 
In the 1992 survey cotinine was measured on all participants using a gas chromatography, mass spectrometric method; the cut point for active smoking was set at $10 \mathrm{ng} / \mathrm{ml}(16)$. Of the self-reported never smokers with genotype data available, $2.3 \%$ had cotinine levels of $10 \mathrm{ng} / \mathrm{ml}$ or more and $0.6 \%$ of 50 $\mathrm{ng} / \mathrm{ml}$ or more. Among current smokers, the mean cotinine was $222 \mathrm{ng} / \mathrm{ml}$ ( $95 \% \mathrm{Cl} 213$ to 230 ).

Depression was reported also in a self-completed questionnaire. Cases were individuals who reported that they had depression diagnosed or treated by a physician during the 12 months preceding the survey. We had data on this variable for the 2002 and 2007 surveys, but in 1992 and 1997 there was no data on depression. Thus, when adjusting for depression, we created a variable including three categories as follows: 0 = no depression $(n=13,161) ; 1=$ depression $(n=1,005) ; 2=$ not known $(n=12,481)$.

\section{Statistical analyses}

Our final analysis sample included 26,647 adults aged $25-74$ years (52.2\% women) with genotype and smoking data available. The mean age of participants was 48.0 years $(S D=13.1)$. We estimated that we were fully powered to detect the association reported by the 2010 analyses, i.e. power was $100 \%$ in order to observe the difference between genotype frequencies. Because no sex by genotype -interaction was observed, men and women were pooled together in the analyses. The association between $B D N F$ Val66Met and ever smoking was modeled using logistic regression adjusted for age and sex. The allele main effects were modeled assuming an additive effect. Additionally, we adjusted for study region. Further, we adjusted the analysis for self-reported depression diagnosed or treated by a physician during the 12 months preceding the survey (no/yes). In a sensitivity analysis we excluded those who reported that they had the above described depression $(n=1,005)$. We also tested gene by depression -interaction, but it was not significant. In order to test pleiotropic effects, we further tested whether BDNF Val66Met was associated with depression in our data set. However, no significant association was seen, also not if adjusted for ever smoking. No gene by ever smoking -interaction on depression was observed. 


\section{Results}

Proportions of never and ever smokers by BDNF genotype are shown in Table $1(\chi 2=9.14, p=0.010)$. We see that the proportions of ever smokers become higher by increasing number of the major (Val) allele (GA and GG genotypes).

The results of logistic regressions are shown in Table 2. When logistic regression was adjusted for sex and age the major (Val) allele was significantly associated with the risk of being a lifetime ever smoker $(\mathrm{OR}=1.07 ; 95 \% \mathrm{Cl} 1.01,1.12 ; \mathrm{p}=.01)$. Further adjustment for area did not change the results $(\mathrm{OR}=1.06$; $95 \% \mathrm{Cl} 1.01,1.12 ; \mathrm{p}=.01)$.

When depression, which itself had a significant and expected association with ever smoking ( $O R=1.58$; $95 \% \mathrm{Cl} 1.37,1.82 ; \mathrm{p}<.001)$, was added to the age and sex adjusted model, the results remained unchanged $(\mathrm{OR}=1.06 ; 95 \% \mathrm{Cl} 1.01,1.12 ; \mathrm{p}=.01)$. Exclusion of depressed individuals had no effect on the results (OR=1.06; 95\%Cl 1.01, 1.12; $p=.02)$.

In order to test pleiotropic effects, we further tested whether BDNF Val66Met was associated with depression in our data set. In this Mendelian randomization analysis, BDNF Val66Met was not associated with depression $(\mathrm{OR}=0.97,95 \% \mathrm{Cl} 0.86$ to $1.10, \mathrm{p}=0.67)$ in a model without smoking. The association of smoking with depression remained strong after adjusting for genotype (OR=1.63, $p=7.2 \mathrm{E}-13)$. No gene by ever smoking -interaction on depression was observed.

\section{Discussion}

Here, we aimed to replicate the finding of the three consortia reporting that BDNF Val66Met is associated with smoking initiation. Our special focus was to test in a large Finnish population-based sample whether the association is independent of depression. We robustly replicated the modest effect reported by the TAG consortium. Interestingly, this association remained significant when adjusting for depression and after excluding depressed individuals.

The association we replicated was based on a combined analysis of three large meta-analyses (6-8). They identified altogether eight BDNF SNPs associated with smoking initiation. The most robustly associated variant was the Val66Met (rs6265). The Odds Ratio (OR) was 1.06 among 143,023 adults. When comparing this effect size with our sex and age adjusted effect size $(\mathrm{OR}=1.07 ; 95 \% \mathrm{Cl} 1.01,1.12$; $\mathrm{p}=.01$ ) we can confirm that the replication was successful even in a smaller but genetically more homogeneous sample of Finns. 
Strengths of the study include that we had a population-based sample originating from the homogenous Finnish population, with little risk of bias from population stratification. There was regional difference in genotype frequencies, but when adjusting for study region, the results did not change. An important strength of this study is the ability to test for the confounding effect of depression. To our knowledge, no other covariates apart from age and sex have been taken into account in earlier studies on BDNF genetic variants and smoking initiation.

Weaknesses of this study include that both smoking behavior and depression are based on self-reported questionnaire data. However, smoking status was biochemically verified in a large proportion (21\%) of participants. Only $2.3 \%$ of self-reported never smokers in the FINRISK 1992 survey had elevated cotinine levels and virtually all current smokers in the FINRISK sample have been reported to have high cotinine levels (16), suggesting that the self-reported smoking status is highly reliable. Also depression was based on self-reported depression diagnosed or treated by a physician during the past 12 months, available for participants of the 2002 and 2007 surveys $(n=14,166)$. To deal with the missing data we added a category 'unknown' into the depression variable. Among adult population the question about having depression diagnosed or treated by a physician is quite clear and easy to answer in an anonymous survey situation. Compared to diagnostic interviews providing clinical diagnosis phenotypes the validity of self-report has been found to be adequate (17).

\section{Conclusions}

The earlier reported association of BDNF Val66Met with smoking initiation was replicated In the Finnish population data. The effect size was very similar to that reported in the 2010 large meta-analyses. Our data suggest that the association of $B D N F$ with smoking initiation is robust and independent of depression.

\section{Conflict of Interest}

Dr. Korhonen has served as a consultant to Pfizer in 2011-2017 on tobacco dependence. Dr. Kaprio has served as a consultant to Pfizer in 2008 on pharmacogenetics of smoking cessation and in 2011-2014 on tobacco dependence. Dr. Salomaa has participated in a conference trip sponsored by Novo Nordisk. 


\section{Funding}

This work was supported by the Sigrid Juselius Foundation (JK), and by the Academy of Finland (309119

to TK and 265240, 263278, 308248, 312073 to JK). ENGAGE - European Network for Genetic and Genomic Epidemiology, FP7-HEALTH-F4-2007, grant agreement number 201413, Academy of Finland Center of Excellence in Complex Disease Genetics (grant numbers: 213506, 129680). VS was supported by the Finnish Foundation for Cardiovascular Research. 


\section{References}

(1) Autry AE, Monteggia LM. Brain-derived neurotrophic factor and neuropsychiatric disorders. Pharmacol Rev 2012 Apr;64(2):238-258.

(2) Lang UE, Sander T, Lohoff FW, Hellweg R, Bajbouj M, Winterer G, et al. Association of the met66 allele of brain-derived neurotrophic factor (BDNF) with smoking. Psychopharmacology (Berl) 2007 Mar;190(4):433-439.

(3) Beuten J, Ma JZ, Payne TJ, Dupont RT, Lou XY, Crews KM, et al. Association of specific haplotypes of neurotrophic tyrosine kinase receptor 2 gene (NTRK2) with vulnerability to nicotine dependence in African-Americans and European-Americans. Biol Psychiatry 2007 Jan 1;61(1):48-55.

(4) Czubak A, Nowakowska E, Kus K, Burda K, Metelska J, Baer-Dubowska W, et al. Influences of chronic venlafaxine, olanzapine and nicotine on the hippocampal and cortical concentrations of brain-derived neurotrophic factor (BDNF). Pharmacol Rep 2009 Nov-Dec;61(6):1017-1023.

(5) Sun D, Huang W, Hwang YY, Zhang Y, Zhang Q, Li MD. Regulation by nicotine of Gpr51 and Ntrk2 expression in various rat brain regions. Neuropsychopharmacology 2007 Jan;32(1):110-116.

(6) Tobacco and Genetics Consortium. Genome-wide meta-analyses identify multiple loci associated with smoking behavior. Nat Genet 2010 May;42(5):441-447.

(7) Thorgeirsson TE, Gudbjartsson DF, Surakka I, Vink JM, Amin N, Geller F, et al. Sequence variants at CHRNB3-CHRNA6 and CYP2A6 affect smoking behavior. Nat Genet 2010 May;42(5):448-453.

(8) Liu JZ, Tozzi F, Waterworth DM, Pillai SG, Muglia P, Middleton L, et al. Meta-analysis and imputation refines the association of 15q25 with smoking quantity. Nat Genet 2010 May;42(5):436-440.

(9) Pei Y, Smith AK, Wang Y, Pan Y, Yang J, Chen Q, et al. The brain-derived neurotrophic-factor (BDNF) val66met polymorphism is associated with geriatric depression: a meta-analysis. Am J Med Genet B Neuropsychiatr Genet 2012 Jul;159B(5):560-566.

(10) Verhagen M, van der Meij A, van Deurzen PA, Janzing JG, Arias-Vasquez A, Buitelaar JK, et al. Metaanalysis of the BDNF Val66Met polymorphism in major depressive disorder: effects of gender and ethnicity. Mol Psychiatry 2010 Mar;15(3):260-271.

(11) Morrell HER, Cohen LM. Cigarette smoking, anxiety and depression. Journal of Psychopathology and Behavioral Assessment 2006;28(4):283-297.

(12) Korhonen T, Broms U, Varjonen J, Romanov K, Koskenvuo M, Kinnunen T, et al. Smoking behaviour as a predictor of depression among Finnish men and women: a prospective cohort study of adult twins.

(13) Rose RJ, Broms U, Korhonen T, Dick DM, Kaprio J. Genetics of Smoking behavior. In: Kim YK, editor. Handbook of Behavior Genetics New York: Springer; 2009. p. 411-432.

(14) Borodulin K, Tolonen H, Jousilahti P, Jula A, Juolevi A, Koskinen S, et al. Cohort Profile: The National FINRISK Study. Int J Epidemiol 2017 Nov 20. 
(15) Hallfors J, Loukola A, Pitkaniemi J, Broms U, Mannisto S, Salomaa V, et al. Scrutiny of the CHRNA5CHRNA3-CHRNB4 smoking behavior locus reveals a novel association with alcohol use in a Finnish population based study. Int J Mol Epidemiol Genet 2013 Jun 25;4(2):109-119.

(16) Vartiainen E, Seppala T, Lillsunde P, Puska P. Validation of self reported smoking by serum cotinine measurement in a community-based study. J Epidemiol Community Health 2002 Mar;56(3):167-170.

(17) Sanchez-Villegas A, Schlatter J, Ortuno F, Lahortiga F, Pla J, Benito S, et al. Validity of a self-reported diagnosis of depression among participants in a cohort study using the Structured Clinical Interview for DSM-IV (SCID-I). BMC Psychiatry 2008 Jun 17;8:43-244X-8-43. 


\section{Tables}

Table 1. Proportions of Never and Ever Smokers by BDNF Genotype (Val66Met) (rs6265)

\begin{tabular}{|l|c|c|c|c|c|c|c|}
\hline & \multicolumn{2}{|c|}{ GG } & \multicolumn{2}{c|}{ GA } & \multicolumn{2}{c|}{ AA } & \\
\hline & $\mathrm{N}$ & $\%$ & $\mathrm{~N}$ & $\%$ & $\mathrm{~N}$ & $\%$ & Total \\
\hline $\begin{array}{l}\text { Never } \\
\text { Smoker }\end{array}$ & 7529 & 39.5 & 2791 & 40.4 & 299 & 44.8 & 10619 \\
\hline $\begin{array}{l}\text { Ever } \\
\text { smoker }\end{array}$ & 11551 & 60.5 & 4109 & 59.6 & 368 & 55.2 & 16028 \\
\hline Total & 19080 & 100 & 6900 & 100 & 667 & 100 & 26647 \\
\hline
\end{tabular}

Table 2. Logistic regressions on the association of the BDNF Genotype (Val66Met) (rs6265) with smoking initiation

\begin{tabular}{|c|c|c|c|c|c|c|}
\hline \multirow{2}{*}{$\begin{array}{c}\text { Outcome } \\
\text { Ever } \\
\text { Smoking }\end{array}$} & \multicolumn{3}{|c|}{$\begin{array}{l}\text { Model } 1(n=26,647) \\
\text { Adjusted for sex and age }\end{array}$} & \multicolumn{3}{|c|}{$\begin{array}{l}\text { Model } 2(n=26,647) \\
\text { Adjusted for sex, age, and depression }\end{array}$} \\
\hline & OR & $95 \% \mathrm{Cl}$ & $p$-value & OR & $95 \% \mathrm{Cl}$ & $p$-value \\
\hline $\mathrm{BDNF}^{1}$ & 1.07 & $1.01,1.12$ & 0.012 & 1.06 & $1.01,1.12$ & 0.013 \\
\hline Depression & & & & & & \\
\hline No & - & - & & 1.00 & & \\
\hline Yes & - & - & - & 1.58 & $1.37,1.82$ & $<0.001$ \\
\hline Not asked & & & & 0.84 & $0.80,0.89$ & $<0.001$ \\
\hline
\end{tabular}

${ }^{1}$ Additive model, BDNF, risk per allele (0, 1, 2 ' $\mathrm{A}$ '-alleles) 